\title{
Correlation between the Success in Mathematics and Language among Pupils of Primary School
}

\author{
Ardita Devolli \\ Assistant Professor, Faculty of Education, University of Pristina "Hasan Prishtina" \\ Email: ardita.devolli@uni-pr.edu
}

\section{Doi:10.5901/ajis.2015.v4n1p75}

\begin{abstract}
The aim of this research is to analyse the correlation between the success in mathematics and language of 140 pupils of third and fourth grades of primary schools in Pristina. The results of the research have shown that there is a low correlation between the variables which test mathematics and language skills and those that deal with the success at school in a respective subject. Based on complete data obtained from this research, it can be concluded that the success of pupils in primary schools, in general, has been over-rated due to the lack of objective assessment by teachers. It is recommended that, in the future, the success of pupils in the subject of mathematics should be assessed with objective tests, in order to increasing their success in natural sciences during their further education.
\end{abstract}

Keywords: mathematics skills, language skills, success at school.

\section{Introduction}

Education is a very important human activity and a necessity for any society for it fashions and models man to be able to function well in his environment. The purpose of education is to equip the citizenry to reshape their society so that the flaws and inequalities are eliminated (Boit at al., 2012, p. 179).

Compared to other fields of human endeavor, mathematics is usually regarded as a subject of great precision in which concepts can be defined accurately to provide a firm foundation for the mathematical theory. The psychological realities are somewhat different. Many concepts we meet in mathematics have been encountered in some form or other before they are formally defined and a complex cognitive structure exists in the mind of every individual, yielding a variety of personal mental images when a concept is evoked (Tall at al., 1981, p. 151). Panaoura (2007, p. 32), believes that mathematics does involve some special mechanisms of representation and mental processing which are appropriate for the representation and processing of quantitative relations. Mechanisms are constrained by the organization and the possibilities of the human brain. Thus, any research about the architecture and the development of mind in respect to mathematics will have to specify the domain-specific processes and functions that it involves, the general potentials and processes of the human mind that sustain and frame its functioning, and their dynamic relations in real time during problem solving. According to the Organization for Economic Co-operation and Development - OECD (2010, p. 23), mathematics is the capacity of an individual to formulate, employ and interpret mathematics in a variety of contexts. It includes reasoning mathematically and using mathematical concepts, procedures, facts and tools to describe, explain and predict phenomena. It assists individuals in recognizing the role that mathematics plays in the world and in making well-founded judgments and decisions that constructive, engaged and reflective citizens would require.

How humans come to learn about the counting system of their culture is closely related to the nature of our initial representation of number, because in order to understand counting we must somehow relate it to our prior number concepts. Thus, studying children's developing understanding of counting may shed light on the nature of our early mathematical knowledge. In order to understand the counting system, that is, to know how counting encodes numerosity, children must know the meanings of (some of) the number words. They must also know, at least implicitly, that each word's position in the number word list relates directly to its meaning, the farther along a word occurs in the list, the greater the numerosity it refers to. Without this knowledge, though children might understand the meaning of a given number word, they would not understand how counting determines which number word applies to any given collection of counted entities. Thus children's developing knowledge of the meanings of the number words is a central part of their understanding of the counting system (Wynn, 1992, p. 220). Linked to this Fuson (1988, cited in Hoard at al., 1999, p. 67), pointed out that the ability to recognize, comprehend, manipulate and produce numbers and number words is 
essential to the development and maintenance of even the most basic mathematical skills.

Problem solving ability in mathematics education is the point where knowledge, thinking ability and daily life come together. Problem solving must include both cognitive and metacognitive processes because a problem-solving individual has to select a strategy and think of alternative strategies as they come across difficulties and changing situations (Yıldırım at al., 2013, p. 411). Linked to this, National Council of Teachers of Mathematics (2000, quoted at Rosli at al., 2013), added that good problem solvers tend to naturally pose problems based on situations they see (p. 53). According to Tall $(2006, p .211)$ teacher as mentor can do a great deal by adopting a connectionist viewpoint to help each learner to address a problem by building on current knowledge. Such connectionism has a problem-solving sense of adventure to make new connections and to use existing connections in innovative ways.

Mathematics instruction according to Schoenfeld (1992, p. 32), should: provide students with a sense of discipline - a sense of its scope, power, uses, and history; develop students' understanding of important concepts in the appropriate core content; provide students the opportunity to explore a broad range of problems and problem situations ranging from exercises to open-ended problems and exploratory situations; help students to develop what might be called a "mathematical point of view" - a predilection to analyze and understand, to perceive structure and structural relationships, to see how things fit together; to develop precision in both written and oral presentation, and to develop the ability to read and use text and other mathematical materials.

Norris (2012, p. 22) stressed that the underlying problems are that mathematics curriculum and assessment have not always been designed around learner or broader economic and educational needs. According to, Tella (2008, p. 28), since it is now glaring that every nation of the world is striving towards the millennium goal of achieving quality education by the year 2015, the teaching of mathematics and pupils' performances in the subject should not be joked with, it must be enhanced because mathematics is the gateway to all disciplines one can think of. The need to start building a mathematician of the future for the achievement of quality education, not to be a mirage, is highly germane.

Human language is a well-organized and well-crafted instrument. That is to say, all the basic components of a language work in tandem in a coherent and systematic manner. They are certainly not a random collection of disparate units. From one perspective, a study of language is basically a study of its systems and subsystems. By treating language as system, we are merely acknowledging that each unit of language, from a single sound to a complex word to a large text-spoken or written-has a character of its own, and each is, in some principled way, delimited by and dependent upon its co-occurring units (Kumaravadivelu, 2006, p. 4).

The assumption that reading is based on language appears to be universally shared. Reading may also depend on the writing system that encodes the language. The exact sense in which these two dependencies are true may not be so clear, or at least not so universally ascribed to. On one perspective, reading is "parasitic" on language and only the relatively trivial achievement of learning to decode print into spoken language stands between the linguistically sophisticated 5- year-old and the achievement of fluent reading (Perffeti, 2013, p. 296). According to Smith (2004, p. 31), the basic insights that a student of reading must grasp are relatively few and easy to explain and to demonstrate. These insights, however, are not always part of the general awareness of educators in the field of reading; they are widely disregarded in many instructional programs and materials and in a good deal of reading research, so that they may appear to be new and even unfamiliar ideas. Ortlieb $(2013$, p. 145) pointed out that the one of the greatest challenges of an elementary school teacher is equipping students with comprehension strategies that transfer to all content areas. Gregorian, president of Carnegie Corporation of New York (cited in Graham and al., 2010, p. 2), stressed that those who enrich themselves by learning to read with understanding and write with skill and clarity do so not only for themselves and their families, but for nation as well. They learn in order to preserve and enhance the record of humanity, to be productive members of a larger community, to be good citizens and good ancestors to those who will follow after them. In an age of globalization, where economies sink or swim on their ability to mine and manage knowledge, as do both individual and national security, we cannot afford to let this generation of ours and, indeed, any other, fall behind the learning curve.

According to William (2011, p. 13), the idea that assessment can support learning is not a new idea. It is inconceivable that those involved in the earliest attempts to communicate ideas, skills, or practices to others did not realize that such attempts could not be guaranteed to be successful, and that effective instruction therefore required evaluation, and adjustment. Brown (2004-05, p. 82), states that to ensure that assessment is part of the learning process; it should be learner-centered assessment and should reflect a learner-centered curriculum. Assessment methods and approaches need to be focused on evidence of achievement rather than the ability to regurgitate information. Inevitably this means a lesser concentration on traditional written assessments, particularly time constrained unseen exams, and a greater emphasis on assessment instruments that measure not just recall of facts, but also the students' abilities to use the material they have learned in live situations. Riley-Ayers (2014, p. 4), states that collecting information from multiple 
sources and analyzing it in the light of children's individual learning needs can support teaching whereby all children continue to learn and thrive.

\section{Purpose of Research}

Purpose of this research is to assess the correlation between the success in mathematics and language among pupils of primary school.

\section{Tested Pupils and Methods}

\subsection{Sample of the tested pupils}

This research consists of a sample of 140 pupils who attend classes in four primary schools of Pristina. The sample covers 78 pupils of third grades and 62 pupils of fourth grades. As far as gender is concerned, 63 are girls and 77 boys. Otherwise, the sample of third grade and fourth grade pupils was chosen because, at this age, the automatism of necessary skills of reading and writing comes into being. Linked to this, we are providing an excerpt from a well-known author on reading and writing disorders, Davis (2001, p. 90), who himself had such problems: "sometime at the age of 9 (third grade) a dyslectic reaches the peak of frustration. If he cannot find ways how to overcome or to overpass his problem, he will remain in the third grade for the rest of his life. The school has already become a burden to him and he is desperate". In other words, if at this age such disorders are not detected and avoided, then this problem will continue to linger for the rest of the life.

\subsection{Sample of variables}

The sample of variables consists of the variable of pupils according to gender (63 girls and 77 boys), the variable of mathematics - MAT (8 mathematics tasks), the variable of language - ANS (10 answers related to reading text), as well as, the variable of success at school, respectively the achievement in mathematics - SUM and Albanian language - SUA at school.

During the assessment, only the tasks solved in a correct way were considered. Therefore, the scale of results in the test on mathematics tasks stretched from $0-8$, while in the variable of language from $0-10$. Apart from the test of assessing mathematics and language skills, the scores of the tested pupils in the subject of mathematics and Albanian language have been analyzed as well.

\subsection{Statistical analysis of results}

For the purpose of reaching the aims of this research, initially were analyzed basic statistical parameters, respectively the arithmetical mean $\left({ }^{\bar{x}}\right)$, standard deviation $(\sigma)$, standard error of arithmetical mean $(\sigma \bar{x})$, as well as minimal results (Min) and maximal results (Max) for the variable of mathematics and language skills. Through the t-test, differences between 140 pupils covered by this research were calculated, while the correlations among the variables of this research were assessed through Spearman correlation coefficient.

\section{Results and Discussion}

\subsection{Differences in math-language skills and success at school between girls and boys of third and fourth grades}

In Table 1, results of canonical discrimination analysis of four variables used in this research have been presented. The table shows that there are small statistical differences $(\mathrm{Sig}=.049)$ between girls and boys of third and fourth grades. 
Table 1: Results of the canonical discrimination analysis of applied variables for girls and boys of third and fourth grades

\begin{tabular}{|c|c|c|c|c|c|c|}
\hline Discriminative Function & Canonical correlation & Wilks' Lambda & Df & Sig & C $_{G}$ & C $_{\mathrm{B}}$ \\
\hline 1 & .260 & .932 & 4 & .049 & .249 & -.205 \\
\hline
\end{tabular}

\begin{tabular}{|c|c|c|}
\hline Variable & $\mathbf{r y}_{\mathbf{y}}$ & $\mathbf{r}$ \\
\hline MAT & 0.187 & 0.868 \\
\hline ANS & 0.796 & 0.646 \\
\hline SUM & -0.969 & 0.438 \\
\hline SUA & 1.014 & 0.421 \\
\hline
\end{tabular}

With an aim of elaborating in more detail the obtained results through the canonical discrimination analysis, calculation of basic statistical parameters has been done: arithmetical mean $(\bar{x})$, standard deviation $(\sigma)$, standard error of arithmetical mean $(\sigma \bar{x})$, minimal results (Min) and maximal results (Max), as well as, the t-test of applied variables for girls and boys of third and fourth grades.

Table 2: Basic statistical parameters of applied variables for girls of third and fourth grades

\begin{tabular}{|c|c|c|c|c|c|}
\hline \multirow{2}{*}{ Variable } & \multicolumn{5}{|c|}{ Girls of 3rd and 4th grades } \\
\cline { 2 - 6 } & $\bar{x}$ & $\boldsymbol{\sigma}$ & $\boldsymbol{\sigma} \bar{x}$ & Min & Max \\
\hline MAT & 7.03 & 1.665 & 0.210 & 0 & 8 \\
\hline ANS & 8.24 & 1.990 & 0.251 & 2 & 10 \\
\hline SUM & 4.44 & 1.044 & 0.132 & 1 & 5 \\
\hline SUA & 4.63 & 0.867 & 0.109 & 1 & 5 \\
\hline
\end{tabular}

Table 3: Basic statistical parameters of applied variables for boys of third and fourth grades

\begin{tabular}{|c|c|c|c|c|c|}
\hline \multirow{2}{*}{ Variable } & \multicolumn{5}{|c|}{ Boys of 3rd and 4th grades } \\
\cline { 2 - 6 } & $\bar{x}$ & $\sigma$ & $\sigma \bar{x}$ & Min & Max \\
\hline MAT & 6.61 & 2.001 & 0.228 & 0 & 8 \\
\hline ANS & 7.23 & 2.270 & 0.259 & 1 & 10 \\
\hline SUM & 4.18 & 1.167 & 0.133 & 1 & 5 \\
\hline SUA & 4.31 & 0.977 & 0.111 & 2 & 5 \\
\hline
\end{tabular}

Table 4: Results of the t-test of applied variables for girls and boys of third and fourth grades

\begin{tabular}{|c|c|c|}
\hline \multirow{2}{*}{ Variable } & \multicolumn{2}{|c|}{ Girls and boys of 3rd and 4th grades } \\
\cline { 2 - 3 } & t-test & 2 Tail Sig \\
\hline MAT & 1.335 & 0.184 \\
\hline ANS & 2.751 & 0.007 \\
\hline SUM & 1.389 & 0.167 \\
\hline SUA & 2.048 & 0.042 \\
\hline
\end{tabular}

Elaboration of obtained results from Tables 2, 3 and 4 shows that there are significant statistical differences in favor of girls of third and fourth grade only in the variables of language skills (ANS), therefore pupils have been further tested as a single group.

\subsection{The link between the applied variables for pupils of third and fourth grades}

With an aim of testing the level of correlation among four variables, Spearman correlation coefficient has been used for the pupils of third and fourth grades. Such a correlation has been used due to the fact that the results of the variables of success in mathematics and Albanian language had not been distributed in a normal way, therefore the testing of the normality of results of the variables has been done. Correlation coefficients among the variables have been calculated: variable of mathematics (MAT), variable of language (ANS), the scores of tested pupils in the subject of mathematics 
(SUM) and Albanian language (SUA).

Table 5: Correlation between the applied variables for pupils of third and fourth grades

\begin{tabular}{|c|c|c|c|c|c|}
\hline \multicolumn{2}{|r|}{ Spearman's rho } & MAT & ANS & SUM & SUA \\
\hline \multirow{3}{*}{ MAT } & Correlation Coefficient & 1.000 & $.294^{* *}$ & $.538^{*+*}$ & $.435^{\text {t* }}$ \\
\hline & Sig. (2-tailed) & & .000 & .000 & .000 \\
\hline & $\mathrm{N}$ & 140 & 140 & 140 & 140 \\
\hline \multirow{3}{*}{ ANS } & Correlation Coefficient & $.294^{* *}$ & 1.000 & $.485^{*+}$ & $.511^{*+*}$ \\
\hline & Sig. (2-tailed) & .000 & & .000 & .000 \\
\hline & $\mathrm{N}$ & 140 & 140 & 140 & 140 \\
\hline \multirow{3}{*}{ SUM } & Correlation Coefficient & $.538^{* *}$ & $.485^{\text {t* }}$ & 1.000 & $.851^{*+}$ \\
\hline & Sig. (2-tailed) & .000 & .000 & . & .000 \\
\hline & $\mathrm{N}$ & 140 & 140 & 140 & 140 \\
\hline \multirow{3}{*}{ SUA } & Correlation Coefficient & $.435^{* *}$ & $.511^{\text {t* }}$ & $.851^{* *}$ & 1.000 \\
\hline & Sig. (2-tailed) & .000 & .000 & .000 & . \\
\hline & $\mathrm{N}$ & 140 & 140 & 140 & 140 \\
\hline
\end{tabular}

**. Correlation is significant at the 0.01 level (2-tailed).

Results from Table 5 show that the correlation between the variables MAT and SUM is $r=.538$. Thus, it can be concluded that the common variance between these two variables is only $25 \%$, meaning that $3 / 4$ of the variance between these two variables is not common. Whereas, as for the correlation between the variables MAT and SUA, it is $r=.435$, showing that the common variance between these two variables is only $16 \%$. The other variance of approximately $84 \%$ relates to the specificities of individual variables. Table 5 also shows that the correlation between the variables ANS and SUM is $r=.485$, which proves that $16 \%$ of the variance is common between these two variables. As for the correlation between the variables ANS and SUM ( $r=.511)$, it can be concluded that its common variance is only $25 \%$. Such results prove that the real knowledge of learners in mathematics and Albanian language do not have many elements in common with the assessment of teacher.

Otherwise, higher correlations $(r=.851)$ have been achieved between the variables related to the success in the subjects of mathematics and Albanian language, thus showing the absence of objective assessment of learners by their teachers included in this research.

\section{Conclusion}

The research has been conducted with a sample of 140 pupils of third and fourth grades attending education in four primary schools of Pristina. Through the canonical analysis and t-test it has been confirmed that there are small differences between genders, therefore pupils have been further tested as a single group. With the help of Spearman's correlations, a conclusion has been reached that there is a low level of correlations between the variables which test such skills and those that deal with the success in the subjects of mathematics and Albanian language of tested pupils.

The results of this research have proven that there is a lack of objective assessment by teachers, since they rely a lot on the overall success of pupils when they assess pupils in the subjects of mathematics and Albanian language. Therefore, it is recommended to apply objective tests when assessing the knowledge of pupils in such subjects. Training of teachers in this regard would be helpful not only in establishing a realistic success of pupils in the subject of mathematics, but also in increasing their success in natural sciences during their further education. The greater the knowledge in mathematics, the greater the general knowledge and skills of pupils will be. Further research in other schools is recommended in order to have a more realistic picture of the success of pupils, particularly in the subjects of natural sciences which constitute the foundation for education of pupils.

\section{References}

Boit, M., Njoki, A. \& Chang'ach, J. K. (2012). The Influence of Examinations on the Stated Curriculum Goals, American International Journal of Contemporary Research, 2(2), 179-182.

Brown, S. (2004-05). Assessment for Learning, Learning and Teaching in Higher Education,1, 81-89. 
Davis, R. D. \& Braun, E. M. (2001). Dar disleksije - Zašto neki od najpametnijih ljudi ne znaju čitati i kako mogu naučiti. Zagreb: Alinea.

Graham, S., and Hebert, M. A. (2010). Writing to read: Evidence for how writing can improve reading. A Carnegie Corporation Time to Act Report. Washington, DC: Alliance for Excellent Education.

Hoard, M. K., Geary, D. C, \& Hamson, C. O. (1999). Numerical and arithmetical cognition: performance of low-and average-IQ children, Mathematical Cognition, 5, 65-91.

Kumaravadivelu, B. (2006). Understanding language teaching. Lawrence Erlbaum Associates, Inc., Publishers.

Norris, E. (2012). Solving the maths problem: International perspectives on mathematics education. London: Royal Society of Arts.

OECD (2010). PISA 2009 Results: What Students Know and Can Do - Student Performance in Reading, Mathematics and Science (Volume I). PISA, OECD Publishing.

Ortlieb, E. (2013). Using Anticipatory Reading Guides to Improve Elementary Students' Comprehension, International Journal of Instruction, 6(2), 145-162.

Panaoura, A. (2007). The interplay of processing efficiency and working memory with the development of metacognitive performance in mathematics, The Montana Mathematics Enthusiast, 4(1), 31-52.

Perfetti, C. A. \& Harris, L. N. (2013). Universal Reading Processes Are Modulated by Language and Writing System, Language Learning and Development, 9, 296-316.

Riley-Ayers, S. (2014). Formative assessment: Guidance for early childhood policymakers (CEELO Policy Report). New Brunswick, NJ: Center on Enhancing Early Learning Outcomes.

Rosli, R., Goldsby, D. \& Capraro, M. M. (2013). Assessing Students' Mathematical Problem-Solving and Problem-Posing Skills, Asian Social Science, 9(16), 54-60.

Schoenfeld, A. H. (1992). Learning to think mathematically: Problem solving, metacognition, and sense-making in mathematics. In D. Grouws (Ed.), Handbook for Research on Mathematics Teaching and Learning. New York: MacMillan.

Smith, F. (2004). Understanding reading: A psycholinguistic analysis of reading and learning to read. Lawrence Erlbaum Associates, Inc., Publishers.

Tall, D. \& Vinner Sh. (1981). Concept image and concept definition in mathematics with particular reference to limits and continuity, Educational Studies in Mathematics, 12, 151-169.

Tall, D. (2006). A theory of mathematical growth through embodiment, symbolism and proof, Annales de didactique et de sciences cognitives, 11, 195-215.

Tella, A. (2008). Achievement of primary school pupils mathematics - Teacher variables as predictors of academic, International Electronic Journal of Elementary Education, 1(1), 16-33.

Wiliam, D. (2011). What is assessment for learning? Studies in Educational Evaluation, 37(1), 3-14.

Wynn, K. (1992). Children's acquisition of the number words and the counting system, Cognitive Psychology, 24, $220-251$.

Yıldırım, S. \& Ersözlü, Z. N. (2013). The relationship between students' metacognitive awareness and their solutions to similar types of mathematical problems, Eurasia Journal of Mathematics, Science \& Technology Education, 9(4), 411-415. 